\title{
Editorial
}

\section{Representatividade da mulher no ensino, na pesquisa e na extensão}

Milena de Mesquita Brandão - https://orcid.org/0000-0003-3294-75331

Letícia Cunico - https://orcid.org/0000-0001-8295-2213²

Magali Inês Pessini - https://orcid.org/0000-0002-8169-7932³

Vitória da Silva Macedo - https://orcid.org/0000-0001-8644-4005

Historicamente fundamentada em uma visão androcêntrica ${ }^{5}$, segundo o sociólogo Pierre Bourdieu, "a divisão entre os sexos parece estar 'na ordem das coisas', como se diz por vezes para falar do que é normal, natural, a ponto de ser inevitável [...]" (2010, p. 17). Nesse sentido, o contexto social elucida a maneira de vermos o mundo e, categoricamente, estear as relações sociais a partir de diferenças biológicas.

A imposição de limites “inseparavelmente corporal e moral” (BOURDIEU, 2010, p. 37) cerceia, ao longo de gerações, a atuação feminina em diferentes espaços, principalmente nos lugares implícita ou explicitamente definidos como masculinos. Tal postura determina

\footnotetext{
${ }^{1}$ Mestra em Arquitetura e Urbanismo pela Universidade Federal de Santa Catarina. Diretora de Extensão e professora no Instituto Federal de Santa Catarina. E-mail: milena.brandao@ifsc.edu.br

2 Doutoranda em Engenharia e Gestão do Conhecimento pela Universidade Federal de Santa Catarina. Professora no Instituto Federal de Santa Catarina. Editora-assistente da Revista Caminho Aberto. E-mail: leticia.cunico@ifsc.edu.br

${ }^{3}$ Doutora em Educação em Ciências Químicas da Vida e Saúde pela Universidade Federal do Rio Grande do Sul. Pedagoga no Instituto Federal de Santa Catarina. Editora-assistente da Revista Caminho Aberto. E-mail: magali.pessini@ifsc.edu.br

${ }^{4}$ Graduanda em Geografia pela Universidade do Estado de Santa Catarina. Editora-assistente da Revista Caminho Aberto. E-mail: vitoria.macedo@ifsc.edu.br

${ }^{5}$ Termo utilizado para explicar representações coletivas, estudos, narrações e investigações a partir de uma visão exclusivamente masculina. $O$ androcentrismo estrutura-se com base na perspectiva de que o ser humano do gênero masculino é o único produtor de opiniões críticas, da realização de análises, único observador. Neste sentido, só as concepções provenientes do gênero masculino teriam relevância concreta.
} 


\section{Editorial}

inclusive "a organização simbólica da divisão social do trabalho" (BOURDIEU, 2010, p. 33), em que a mulher é excluída de lugares ditos mais "nobres".

Só uma extensa jornada de lutas e conquistas, de um trabalho incessantemente recomeçado, propicia o desprendimento de construções sociais. Construções essas que já não cabem para a instauração de um movimento de âmbito mundial que traz como um de seus objetivos "Alcançar a igualdade de gênero e empoderar todas as mulheres e meninas" (ODS BRASIL, 2021).

Carla Pinsky e Joana Maria Pedro colocam que, diferente de meados da década de 1980, hoje encontramos um maior acesso a pesquisas e produções acadêmicas cujo objeto de estudo é centrado na mulher (PINSKY; PEDRO, 2015). Olhares atentos são lançados no estudo de diferentes recortes temáticos da mulher na educação, família, trabalho, direito, violência, etnias e na própria construção de sua imagem na sociedade. Mas, mesmo com a crescente atenção a esse tema e com as mulheres representando cerca de $52 \%$ da população brasileira (PNAD, 2019), o Brasil ainda apresenta altos índices de desigualdade de gênero (IBGE, 2021).

Ao utilizarmos dados estatísticos sobre os indicadores sociais das mulheres no Brasil, avaliamos pertinente elucidar neste editorial a seguinte informação:

É importante sublinhar a diferença entre estatísticas desagregadas por sexo e estatísticas de gênero. A palavra "sexo" refere-se aqui às diferenças biológicas entre homens e mulheres. "Gênero", por sua vez, refere-se às diferenças socialmente construídas em atributos e oportunidades associadas com o sexo feminino ou masculino e as interações e relações sociais entre homens e mulheres (IBGE, 2021, p. 2).

Adentrando brevemente no conceito de gênero, encontramos as contribuições da historiadora Joan Scott (1989, p. 7), que também reflete sobre o conceito deste termo e o vocabulário que o cerca. Conforme a autora, o termo "gênero" engloba a discussão dos papéis sociais de homens e mulheres, contestando a ideia de que as mulheres seriam mais frágeis pela possibilidade de se tornarem mães.

Ao considerarmos a extensão como um "processo interdisciplinar, político educacional, cultural, científico, tecnológico" (BRASIL, 2018), que envolve a comunidade acadêmica e outros setores da sociedade, se faz necessária uma exposição acerca da representatividade da mulher nesse panorama. Neste editorial, priorizamos como recorte uma das diretrizes promulgada pelo Fórum de Pró-Reitores de Extensão das Instituições 


\section{Editorial}

Públicas de Educação Superior Brasileiras (FORPROEX, 2012): a indissociabilidade do ensino, pesquisa e extensão.

A educação formal e pública das mulheres precisou romper várias barreiras, entre elas a segregação sexual, o ideário de uma educação mais restrita em função da imagem de fragilidade socialmente construída, além da carga atribuída ao papel da maternidade (ROSEMBERG, 2015). O acesso à educação pelas mulheres é, no Brasil, um fato relativamente recente. Segundo Rosemberg (2015), de 1872 a 1950, os índices de analfabetismo de mulheres estavam consideravelmente acima dos homens. Gradualmente, essa realidade se altera e, em 1990, há uma inversão nos números.

Atualmente, no que se refere aos índices de formação inicial e acadêmica, segundo o IBGE (2019), as mulheres possuem maior nível de escolaridade que os homens no Brasil. A disparidade de gênero no quesito educação tem início na análise das taxas de frequência escolar líquida ${ }^{6}$. Nos anos iniciais do ensino fundamental, homens e mulheres possuem um índice igualitário de 95,8\% de frequência escolar. Contudo, esse cenário se altera progressivamente a partir das próximas etapas de qualificação estudantil dos indivíduos, até o ingresso no ensino superior. Observando os dados de frequência universitária, o índice das mulheres é de $29,7 \%$, contra $21,5 \%$ dos homens. Os números revelam uma diferença de $8,2 \%$.

Ainda na temática formação estudantil, no que tange à conclusão das escalas educacionais, o estudo aponta que, na categoria de observação dos indivíduos com 25 anos ou mais, cerca de $40,4 \%$ dos homens não possuem instrução ou não concluíram o ensino fundamental, enquanto, conforme os dados das mulheres, essa porcentagem é de $37,1 \%$. No ensino superior, na faixa etária entre os 25 e os 34 anos, cerca de $25,1 \%$ das mulheres, durante o período de realização da análise (IBGE, 2019), já haviam finalizado o ensino superior. Averiguando os dados dos homens, essa porcentagem declina para 18,3\%. Esta circunstância revela uma diferença de 6,8 pontos percentuais entre gêneros na qualificação superior.

Ademais, o IBGE apontou, ainda, que em 2019 (dados mais recentes), a possibilidade de estar frequentando ou já ter finalizado o ensino superior, no que diz respeito às mulheres

\footnotetext{
${ }^{6}$ A frequência escolar líquida representa o percentual da população estudantil em determinada faixa etária que se encontra devidamente matriculada e está frequentando diariamente, de forma contínua, o nível de ensino adequado à sua idade (ABRINQ, 2016).
} 


\section{Editorial}

que se encaixavam na faixa etária dos 18 a 24 anos, era $38 \%$ maior do que a dos homens com a mesma idade.

Temos até aqui um recorte breve do cenário da participação de meninas, jovens e mulheres na educação em âmbito geral. É interessante, dentro desse panorama, observarmos também os dados do Conselho Nacional de Desenvolvimento Científico e Tecnológico (CNPq), que considera mais de 134 mil doutores no país, dos quais, as doutoras são responsáveis por $47 \%$ desse total. No entanto, nos níveis mais altos de pesquisa, há apenas 363 pesquisadoras, contra 1.023 pesquisadores, ou seja, elas ocupam 26\% dos cargos mais altos da ciência (BRASIL, 2020).

De acordo com a Coordenação de Aperfeiçoamento de Pessoal de Nível Superior (Capes), dos 364.094 estudantes de programas de pós-graduação no país, mais da metade, 195.301, são mulheres. Atuando como professores de especialização, mestrado ou doutorado, há 76.894 profissionais, dos quais 33.318 são professoras, representando menos da metade (BRASIL, 2020).

As mulheres são maioria na concessão de bolsas para Iniciação Científica (55\%), no mestrado (52\%), no doutorado (50\%) e no pós-doutorado (53\%), segundo dados do CNPq, Inep e Parent in Science. Porém, as bolsas de Produtividade em Pesquisa (PQ) para mulheres correspondem a apenas $36 \%$ do total. As bolsas em PQ são voltadas para pesquisadores que já têm o título de doutor ou livre-docente e que tenham uma produção científica de destaque em suas áreas de conhecimento (BRASIL, 2020).

Em relação às áreas de pesquisa, as mulheres são maioria em cursos relacionados a artes, biológicas, humanas, saúde e ciências sociais aplicadas, enquanto os homens são maioria nas áreas de CTEM ${ }^{7}$ (BRASIL, 2020). A historiadora da ciência Londa Schiebinger (2001, p. 78) afirma que as mulheres acabam se concentrando nas ciências apontadas como mais leves (soft) e de remunerações mais baixas. Nas áreas consideradas como mais difíceis (hard), onde existe mais prestígio e melhores salários, os profissionais homens são a maioria. De acordo com Michele Ferrand (1994, p. 359), "o destino escolar e profissional das meninas parece paradoxal". As meninas apresentam melhor desempenho (com melhores notas e

\footnotetext{
${ }^{7}$ A sigla CTEM tem origem do inglês Science, Technology, Engineering and Mathematics, ou simplesmente STEM. No português, ela ganha a tradução "CTEM" e é utilizada para representar as áreas de Ciências, Tecnologia, Engenharia e Matemática.
} 


\title{
Editorial
}

menos repetências) durante toda a formação básica, quando comparadas aos meninos. A autora complementa (1994):

\begin{abstract}
Como explicar esse paradoxo da excelência das moças e de sua exclusão paralela dos caminhos da excelência? O rigor da seleção não pode ser reduzido a uma questão de nível, pois as diferenças dos resultados entre meninas e meninos em geral são em benefício daquelas, e são muito pequenas (embora seja verdade que é nas disciplinas científicas que se encontram) quando são em benefício dos últimos. Como explicar que, em vez de coincidir com a implantação da escola mista, os tipos de formação e de carreiras seguidas pelos meninos e as meninas mostrem fortes disparidades, as moças se orientando majoritariamente para as disciplinas literárias, os rapazes para as disciplinas científicas? (p. 359).
\end{abstract}

Dados do Global Gender Gap Report do Fórum Econômico Mundial (WORLD ECONOMIC FORUM, 2021, p. 36) mostram que, no Brasil, apenas 10,7\% das mulheres brasileiras estão matriculadas em cursos superiores em CTEM, contra $28,6 \%$ dos homens. Este dado evidencia a necessidade de criar políticas públicas de incentivo da participação de mulheres nos cursos mais tecnológicos, o que pode contribuir para a abertura de melhores oportunidades econômicas.

A criação de políticas públicas visando incentivar a participação das mulheres nos cursos voltados para áreas tecnológicas possibilita a abertura para análise de dados relevantes, que contribuirão consideravelmente com as reflexões da presente discussão. Estes são voltados para a observação da representação das mulheres na gestão pública, estatal. Na política brasileira, a disparidade entre gêneros é expressiva. Segundo o IBGE, apenas $16 \%$ dos vereadores eleitos em 2020 eram mulheres.

Quanto aos dados de representatividade parlamentar, atuação na câmara dos deputados, a porcentagem é ainda menor: apenas 14,8\% (IBGE, 2021) dos atuantes na câmara são mulheres. Essas estimativas colocam o Brasil como um dos países com a menor proporção de mulheres atuando na política. Também é interessante evidenciar que, conforme o Instituto, esses aspectos nos posicionam na 142a posição de um ranking com dados de 190 países relativos à representatividade das mulheres na política. Ou seja, tendo em vista que majoritariamente a população brasileira é composta por mulheres, fica visivelmente nítido o caso de sub-representação política.

A Figura 1 apresenta lacunas de gênero no Brasil, onde é possível comparar a situação do país (mancha azul claro) com a média mundial (linha azul escura) no que se refere à 


\section{Editorial}

desigualdade de gênero. Esses dados do Fórum Econômico Mundial corroboram com os dados do IBGE, mostrando a disparidade na representação política.

Figura 1 - Gráfico lacunas de gênero no Brasil

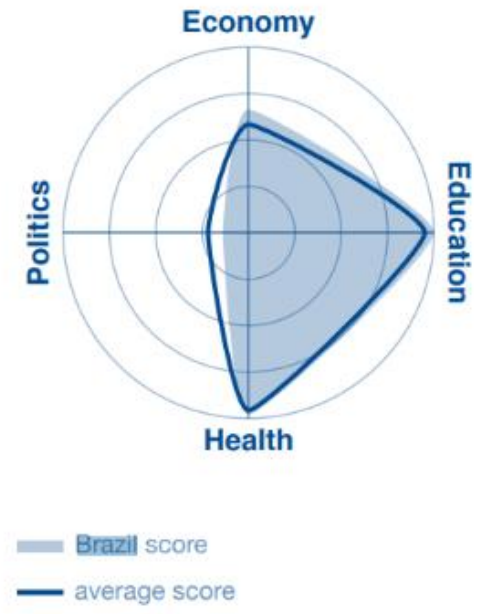

Fonte: Dados coletados do Global Gender Gap Report (WORLD ECONOMIC FORUM, 2021, p. 133).

Aqui, consideramos pertinente informar, a cunho de esclarecimento, que esse material é produzido anualmente pelo Fórum Econômico Mundial. Esse tipo de publicação é crucial para que se compreenda os índices de disparidades entre homens e mulheres no mundo. É por meio da compreensão dessas informações que ações práticas, para mitigar o presente cenário, podem receber ainda mais atenção por parte dos gestores públicos.

Ademais, entender o contexto de educação, representatividade política, que circunda a figura da mulher estabelece uma estreita relação com suas conquistas e representações no mundo do trabalho. No PNAD de 2019, o IBGE identificou que 37,4\% das mulheres no Brasil ocupam cargos gerenciais - contra $62,6 \%$, dos homens. 


\title{
Editorial
}

Levando em conta esses dados, considerar as diferenças no nível de qualificação entre homens e mulheres se torna essencial, visto que o nível de qualificação para concorrer em processos seletivos, ou na hora de firmar contratações, é primordial. Refletindo acerca desses levantamentos e com vistas à defesa de um processo formativo voltado ao mundo do trabalho, destacamos: "A escola e os sistemas de ensino precisam ter uma visão crítica do mercado de trabalho e construir o processo formativo no qual, ao tempo em que proporcionam acesso aos conhecimentos, contribuam para que o sujeito se insira no mundo do trabalho e também questione a lógica desse mesmo mercado" (RAMOS, 2005, p. 23).

Iniciamos então o processo de análise dessas diferenças, por meio da observação de um ponto consideravelmente relevante, segundo Rosemberg (2015):

\begin{abstract}
A verdade é que o acesso mais intenso das mulheres à educação escolar não tem garantido de fato uma igualdade de oportunidade a toda e qualquer mulher, bem como a experiência da coeducação; isto é, meninos e meninas, rapazes e moças não vivenciam o mesmo currículo, pois a antiga segregação sexual escolar, com seus currículos diferenciados, deixou suas marcas (p. 449).
\end{abstract}

Verificamos até aqui números da educação em âmbito geral e números relacionados especificamente à pesquisa, mas e quanto à indissociabilidade ensino, pesquisa e extensão? Na Constituição da República Federativa do Brasil, em seu Art. 207, lê-se: "As universidades [...] obedecerão ao princípio de indissociabilidade entre ensino, pesquisa e extensão".

No Brasil, o termo extensão aparece no Estatuto das Universidades Brasileiras (Decreto n 19.851, 11/04/31), em seu art. 35: “f) cursos de extensão universitária, destinados a prolongar, em benefício coletivo, a atividade técnica e científica dos institutos universitários" (BRASIL, 2001). O trecho do documento da XXVIII Reunião Plenária do Conselho de Reitores das Universidades Brasileiras (CRUB), realizada em 1979, denomina extensão como: “Decorre da extensão o conhecimento da realidade, a formação de consciência crítica e enriquecimento curricular, beneficiando corpo docente, discente e administrativo" (MORAES FILHO; SILVEIRA, 2011, p. 5).

O Fórum de Pró-Reitores de Extensão das Instituições Públicas de Educação Superior Brasileiras (FORPROEX) foi criado em 1987, assumindo importante papel e conceituando a Extensão. Tal conceito é revisado e reafirmado na Resolução CNE/CES no 7, de 2018: 


\section{Editorial}

A Extensão na Educação Superior Brasileira é a atividade que se integra à matriz curricular e à organização da pesquisa, constituindo-se em processo interdisciplinar, político educacional, cultural, científico, tecnológico, que promove a interação transformadora entre as instituições de ensino superior e os outros setores da sociedade, por meio da produção e da aplicação do conhecimento, em articulação permanente com o ensino e a pesquisa.

A Extensão, no Brasil, passou por inúmeros entendimentos ao longo do tempo, dentre eles: difusão cultural ou científica, prestação de serviço, assistência social e desenvolvimento (VIEIRA, 2014). É compreendida pelo autor como o caminho de consolidação de responsabilidade e compromisso social e também como dimensão intrínseca da formação acadêmica e do conhecimento produzidos na e pela Instituição de ensino.

Ainda sobre a Política Nacional de Extensão Universitária, esta discorre que a "extensão deve ser um instrumento de mudança social em direção à justiça, à solidariedade e à democracia" (FORPROEX, 2012, p. 4). A Política afirma "a transformação da Extensão em um instrumento efetivo de mudança da instituição de ensino e da sociedade, em direção à justiça social e ao aprofundamento da democracia"; da sensação de que se vive em uma era de grandes transformações "e a busca de novas oportunidades que se descortinam no contexto internacional e na realidade brasileira" (FORPROEX, 2012, p. 9).

As ações promovidas pela extensão devem objetivar o acesso da comunidade aos saberes científicos, filosóficos, culturais e tecnológicos, que conferem um caráter dialógico à relação entre as duas. Cavalcante $(2002$, p. 18$)$ reitera que o "processo educativo, cultural e científico, articulado de forma indissociável ao Ensino e à Pesquisa, [...] viabiliza uma relação transformadora entre universidade e sociedade".

É nesse sentido que a extensão deve:

[...] priorizar práticas voltadas para o atendimento das necessidades sociais (por exemplo, habitação, produção de alimentos, geração de emprego, redistribuição de renda), relacionadas com as áreas de Comunicação, Cultura, Direitos Humanos e Justiça, Educação, Meio Ambiente, Saúde, Tecnologia e Produção, Trabalho (FOPROEX, 2012, p. 5).

A busca de relevância para o conhecimento produzido e compartilhado pela instituição de educação superior aporta com segurança nas atividades de extensão. O objetivo da extensão é o elo da instituição com a sociedade, resultado das atividades de ensino e pesquisa, reafirmando o compromisso social das instituições de ensino superior, 


\section{Editorial}

concretizando a promoção e garantia do desenvolvimento social, bem como as demandas da comunidade.

Nesse contexto, fazendo buscas em base de dados institucionais como CAPES, CNPq, bem como em censos da educação superior, não são encontrados dados referentes à participação das mulheres nas ações extensionistas. A não realização de levantamentos dessas informações denota uma problemática - em razão de que compreender os índices de atuação de homens e mulheres nas ações de extensão é crucial para que se tenha uma noção de representatividade. Tal fato auxilia na visualização das dissimilitudes entre gêneros.

Análises no sentido de se visualizar essas diferenciações são feitas em escala nacional e internacional, porque se tem entendimento da importância da percepção desses aspectos. Levando em conta, igualmente, as adversidades que rodearam a trajetória das mulheres ao longo da história e que ainda existem. Aqui, nos referimos às diversas situações obscuras que as mulheres enfrentaram e que ainda batalham para combater e desmistificar.

Foi pensando em dar visibilidade a essa situação no Brasil que o IBGE, no ano de 2014, através do Sistema Nacional de Informações de Gênero (SNIG), firmou um convênio com a Secretaria de Políticas para as Mulheres, para elaborar um estudo sobre estatísticas de gênero ${ }^{8}$. Inicialmente, o estudo teve como base os dados levantados no Censo Demográfico do ano de 2010. Além disso, esta pesquisa foi a primeira do SNIG, que elabora estudos desde o ano de 2006, a ganhar uma versão impressa (IBGE, 2021).

O Instituto Brasileiro de Geografia e Estatística (IBGE), como um órgão que possui responsabilidade nacional e tem deveres com a nação, promove um trabalho extremamente importante ao dedicar-se em revelar os indicativos sociais das mulheres no Brasil. Os dados são fundamentais para que políticas públicas em prol da defesa da mulher sejam elaboradas e consolidadas; para que, assim, o cenário de desigualdade entre gêneros seja revertido no país.

Deste modo, espera-se que, num futuro próximo, os dados de atuação nas ações de extensão sejam contabilizados. Para que, assim, tenhamos uma perspectiva do papel e atuação de extensionistas mulheres. Afinal, a extensão tem papel relevante na tríade acadêmica, como interventora direta na comunidade externa às instituições de ensino. $E$ considerando que majoritariamente a população brasileira é composta por mulheres, é

${ }^{8}$ Leitores interessados, conferir em: https://biblioteca.ibge.gov.br/visualizacao/livros/liv88941.pdf 


\section{Editorial}

necessário que tenhamos mulheres pensando e trabalhando por mulheres, com mulheres, o que chamamos de sororidade. Considerando os objetivos da extensão, ter mulheres desenvolvendo suas ações é primordial.

Ainda sobre a Extensão, Santos (2005, p. 225) ressalta:

Numa sociedade cuja quantidade e qualidade de vida assenta em configurações cada vez mais complexas de saberes, a legitimidade da universidade só será cumprida quando as atividades, hoje ditas de extensão, se aprofundarem tanto que desapareçam enquanto tais e passem a ser parte integrante das atividades de investigação e de ensino.

É partindo dessas premissas que o Volume 16 da revista Caminho Aberto inicia com alguns trabalhos convidativos à reflexão da temática representatividade da mulher. Para a entrevista desta edição, temos como convidada a professora e pesquisadora Miriam Pillar Grossi, referência em estudos de gênero e panorama da mulher. Já o artigo que abre este número preocupa-se em debater sobre a questão da violência contra a mulher. Trata-se de uma intervenção desenvolvida por um grupo de extensionistas, mulheres, da Universidade Federal do Rio Grande (FURG).

Por fim, finalizamos refletindo que, entre signos socialmente construídos, retratam um "fechamento do corpo feminino" entre "braços cruzados sobre o peito, pernas unidas, vestes amarradas" (BOURDIEU, 2010, p. 25), e expomos aqui um caminho de legitimação da mulher em seu potencial como estudante, educadora, pesquisadora, gestora e extensionista. E como protagonistas na sociedade em que vivemos, comprometamos a todos nós, leitores e autores, à responsabilidade da construção de novos signos.

\section{REFERÊNCIAS}

BOURDIEU, Pierre. A dominação masculina. Tradução: Maria Helena Kuhner. 9. ed. Rio de Janeiro: Bertrand Brasil, 2010.

BRASIL. Constituição da República Federativa do Brasil de 1988. Disponível em: http://www.planalto.gov.br/ccivil 03/constituicao/constituicao.htm. Acesso em: 30 nov. 2021. 


\section{Editorial}

http://portal.mec.gov.br/index.php?option=com content\&view=article\&id=86161: mulheres sao-maioria-entre-bolsistas-de-mestrado-e-doutorado-no-brasil\&catid=225. Acesso em: 17 nov. 2021.

BRASIL. Resolução no 7, de 18 de dezembro de 2018. Estabelece as Diretrizes para a Extensão na Educação Superior Brasileira e regimenta o disposto na Meta 12.7 da Lei no 13.005/2014, que aprova o Plano Nacional de Educação - PNE 2014-2024 e dá outras providências. Brasília, DF: Câmara de Educação Superior do Conselho Nacional de Educação, 2018b. Disponível em: https://www.in.gov.br/materia//asset_publisher/Kujrw0TZC2Mb/content/id/55877808. Acesso em: 17 nov. 2021.

CAVALCANTE, Joseneide Franklin. Evolução do ensino Superior-graduação - 1980/1998. Brasília: Instituto Nacional de Estudos e Pesquisas Educacionais, 2002.

FERRAND, Michèle. Exclusão das Mulheres da Prática das Ciências: Uma manifestação sutil da dominação masculina. Revista Estudos Feministas, Florianópolis, p. 358-367, jan. 1994. Disponível em: https://periodicos.ufsc.br/index.php/ref/article/view/16169/14720. Acesso em: 06 dez. 2021.

FORPROEX. Política Nacional de Extensão Universitária. Manaus, 2012. Disponível em: https://proex.ufsc.br/files/2016/04/Pol\%C3\%ADtica-Nacional-de-Extens\%C3\%A3oUniversit\%C3\%A1ria-e-book.pdf. Acesso em: 17 nov. 2021.

FUNDAÇÃO ABRINQ. Taxa de escolarização bruta e líquida no Ensino Fundamental. São Paulo, 2016. Disponível em: https://observatoriocrianca.org.br/cenarioinfancia/temas/ensino-fundamental/554-taxa-de-escolarizacao-bruta-e-liquida-no-ensinofundamental?filters=1,113. Acesso em: $10 \mathrm{dez} .2021$.

INSTITUTO BRASILEIRO DE GEOGRAFIA E ESTATÍ́sTICA (IBGE). Pesquisa Nacional por Amostra de Domicílios Contínua PNAD. Brasil: Instituto Brasileiro de Geografia e Estatística (IBGE), 2019. Disponível em: https://biblioteca.ibge.gov.br/visualizacao/livros/liv101651_notas_tecnicas.pdf. Acesso em: 10 nov. 2021.

INSTITUTO BRASILEIRO DE GEOGRAFIA E ESTATÍ́STICA (IBGE). Estatísticas de Gênero Indicadores sociais das mulheres no Brasil 2a edição. Brasil: Instituto Brasileiro de Geografia e Estatística (IBGE), 2021. Disponível em:

https://biblioteca.ibge.gov.br/visualizacao/livros/liv101784_informativo.pdf. Acesso em: 10 nov. 2021. 


\section{Editorial}

MORAES FILHO, Waldenor Barros; SILVEIRA, Hélder Eterno da. Extensão na formação profissional: desafios e possibilidades. Uberlândia: EDUFU, 2011. Disponível em: https://curricularizacaoda extensao.ifsc.edu.br/files/2016/06/5_Extensao_na_Formacao_Profissional_Desafios_e_Poss ibilidades.pdf. Acesso em: 10 out. 2017.

ODS BRASIL. Objetivos de desenvolvimento sustentável. Disponível em: https://odsbrasil.gov.br/objetivo/objetivo?n=5. Acesso em: 29 nov. 2021

PINSKY, Carla Bassanezi; PEDRO, Joana Maria. Nova história das mulheres no Brasil. São Paulo: Contexto, 2013.

RAMOS, Marise Nogueira. Possibilidades e Desafios na Organização do Currículo Integrado. In: RAMOS, Marise Nogueira; FRIGOTTO, Gaudêncio; CIAVATTA, Maria (Orgs.). Ensino Médio Integrado: Concepção e Contradições. São Paulo: Cortez, 2005.

ROSEMBERG, Fúlvia. Educação: Mulheres educadas e a educação de mulheres. In: PINSKY, Carla Bassanezi; PEDRO, Joana Maria (Orgs.). Nova história das mulheres no Brasil. São Paulo: Contexto, 2013.

SANTOS, Marcos Ferreira. O espaço crepuscular: mito-hermenêutica e jornada interpretativa em cidades históricas. In: PITTA, Daniele Perin Rocha (Org.). Ritmos do imaginário. Recife: UFPE, 2005. p. 59-99.

SCHIEBINGER, Londa. O feminismo mudou a ciência? Tradução: Raul Fiker. Bauru, SP: EDUSC, 2001. 384p. (Coleção Mulher)

SCOTT, Joan. Gênero: uma categoria útil para análise histórica. Tradução: Christine Rufino Dabat e Maria Betânia Ávila. São Paulo: EDUSP, 1989. Disponível em: https://disciplinas.stoa.usp.br/pluginfile.php/185058/mod_resource/content/2/GêneroJoan Scott.pdf. Acesso em: 06 dez. 2021.

VIEIRA, Carina Silva. Extensão Universitária: concepções presentes na formalização, propostas e práticas desenvolvidas na Universidade Federal do Paraná (1968-1987). 2014. Dissertação (Mestrado em Educação) - Universidade Federal do Paraná, Curitiba.

WORLD ECONOMIC FORUM. Global Gender Gap Report: Insight Report. Genebra: World Economic Forum Davos, 2021. Disponível em: https://www3.weforum.org/docs/WEF GGGR 2021.pdf. Acesso em: 06 dez. 2021. 


\section{Editorial}

